ACTA

AMAZONICA

\title{
Hybotinae (Diptera, Hybotidae) do Parque Nacional do Jaú, Amazonas, Brasil, com descrição de cinco espécies novas de Syneches Walker
}

Rosaly ALE-ROCHA ${ }^{1}$, Renata Magalhães VIEIRA²

RESUMO

A composição de Hybotinae do Parque Nacional do Jaú foi estudada. Dezesseis espécies de Hybotinae são registradas e cinco espécies novas de Syneches Walker são descritas e ilustradas: Syneches hispidus sp. nov., S. jauensis sp. nov., S. longiflagellatus sp. nov., $S$. rafaeli sp. nov. e $S$. vidali sp. nov.

PALAVRAS-ChAVE: Região Amazônica, Diptera, Empidoidea, Syneches, Taxonomia

\section{Hybotinae (Diptera, Hybotidae) of the National Park of Jaú, Amazonas, Brazil, with description of five new species of Syneches Walker}

\section{ABSTRACT}

The composition of Hybotinae of the National Park of Jaú was studied. Sixteen species of Hybotinae are recorded and five new species of Syneches Walker are described and illustrated: Syneches hispidus sp. nov., S. jauensis sp. nov., S. longiflagellatus sp. nov., S. rafaeli sp. nov. and $S$. vidali sp. nov.

KEYWORDS: Amazon Region, Diptera, Empidoidea, Syneches, Taxonomy

${ }^{1}$ Coordenação de Pesquisa em Entomologia, Instituto Nacional de Pesquisas da Amazônia - CPEN/INPA. Av. André Araújo, 2936 Campus II - Aleixo. 


\section{INTRODUÇÃO}

A família Hybotidae (Diptera) é cosmopolita e tem sido bastante estudada nas regiōes Neártica e Paleártica, mas seu conhecimento na região Neotropical é ainda incipiente, com muitas espécies a serem descritas. Hybotinae é uma das subfamílias mais diversificadas de Hybotidae, inclui 13 gêneros e atualmente cerca de 120 espécies registradas na região Neotropical (Smith, 1967; Ale-Rocha, 1999, 2000, 2001, 2002a,b, 2004; Ale-Rocha \& Carvalho, 2003). A fauna amazônica de Hybotinae vem sendo mais intensamente estudada, mas informações sobre sua distribuição estão fragmentadas. Sete gêneros ocorrem na Região Amazônica tendo sido registrados até agora 5 gêneros e 13 espécies para a Amazônia Brasileira (Ale-Rocha, 2000, 2002a,b, 2004; Ale-Rocha \& Rafael, 1995). São moscas predadoras, altamente diversificadas e facilmente coletadas com armadilhas de interceptação de vôo. São caracterizados pela condição holóptica em ambos os sexos, com as facetas superiores maiores que as inferiores, asa sem álula, célula discal presente, célula cup tão ou mais longa que a bm com ângulo externo agudo e tíbia anterior com glândula sub-basal na face posterior.

O Parque Nacional do Jaú (PNJ), uma das áreas protegidas mais extensas do Brasil, tem tido sua biodiversidade pesquisada visando sua conservação. Material referente a Hybotinae obtido em diversas excursōes ao PNJ trouxe novas informações acerca da sua diversidade.

\section{MATERIAL E MÉTODOS}

O Parque Nacional do Jaú tem aproximadamente 22.720 $\mathrm{km}^{2}$. Está situado a $200 \mathrm{Km}$ a noroeste de Manaus e abrange as bacias hidrográficas dos rios Jaú e Unini, afluentes da margem direita do Rio Negro. Ocupando a região central do Parque está o rio Jaú. As paisagens do PNJ compõem mosaicos de vários tipos de vegetação: floresta tropical densa (floresta primária), matas de igapó, campinas, campinaranas e buritizais (Borges et al., 2004).

O material estudado está depositado na Coleção de Invertebrados do INPA, é proveniente de coletas realizadas durante nove excursōes feitas ao PNJ entre os anos de 1993 e 2001 através do projeto Janelas para a Biodiversidade (Borges et al., 2004), além de material coletado no parque em excursôes anteriores. Material adicional disponível de outras localidades foi utilizado para completar as séries-tipo das espécies novas.

As coletas foram feitas com armadilhas de interceptação de vôo tipo Malaise e Armadilha Suspensa (Rafael \& Gorayeb, 1982) tanto em floresta primária quanto em formações de campina e campinarana.

Os termos e abreviações usados nas descrições das espécies seguem McAlpine (1981). Homologias da terminália do macho seguem Cumming et al. (1995). Abreviaçôes referentes à posição das cerdas nas pernas usadas nas descrições são: $\mathrm{A}=$ anterior; $\mathrm{AV}$ = ântero-ventral; $\mathrm{AD}$ = ântero-dorsal; $\mathrm{D}=$ dorsal; $\mathrm{P}=$ posterior $; \mathrm{PD}=$ póstero-dorsal; $\mathrm{PV}=$ póstero-ventral; $\mathrm{V}$ $=$ ventral.

A terminália foi removida do abdome, tratada com ácido lático a quente e colocada em microtubo contendo glicerina. As asas foram ilustradas depois de removidas do corpo e montadas entre lamínulas coladas a um pedaço de cartolina. Os microtubos e as lamínulas foram presos ao alfinetes do espécime correspondente.

\section{RESULTADOS}

Foram examinados 384 exemplares de Hybotinae dos gêneros Euhybus Coquillett e Syneches Walker coletados no Parque Nacional do Jaú. Foram identificadas 10 espécies de Syneches, 5 delas novas, e 6 espécies de Euhybus. Trinta e oito exemplares de outras localidades foram utilizados para completar as séries-tipo das espécies novas.

\section{Eubybus Coquillett 1895}

Diagnose. Castanhos a pretos, geralmente brilhantes; flagelo coniforme, arista apical, nua; probóscide curta e robusta; labelo desenvolvido, membranoso; pseudotraquéias presentes; holóptico; palpo com 1 cerda apical longa; Rs curta; pulvilos tarsais anteriores e médios longos, posteriores curtos; terminália masculina assimétrica.

Distribuição geográfica: ocorre exclusivamente no Novo Mundo, do Canadá à Argentina (ausente no Chile).

\section{Euhybus amazonicus Ale-Rocha, 2002}

Espécie descrita da Amazônia por Ale-Rocha (2002a). Até o momento sua distribuição era conhecida apenas para o extremo oeste da Amazônia Brasileira, Equador e Colômbia. Este é o primeiro registro da espécie no PNJ.

Material examinado. BRASIL, Amazonas, Rio Jaú, Meriti, Novo Airão, 04-10.vi.1994, 1 fêmea; Parque Nacional do Jaú, Rio Unini, Democracia, 014254S, 615432W, 20-24.vi.1996, A.L. Henriques, J. Vidal \& F.L. Oliveira, 1 macho, 2 fêmeas (todos depositados no INPA).

Registros geográficos: Equador, Colômbia, Brasil (Amazonas).

\section{Eubybus dimidiatus (Walker, 1852)}

Espécie amplamente distribuída na América do Sul. Foi descrita de exemplar da Serra do Cachimbo (Pará) e revisada por Smith (1962) e Ale-Rocha (2002a) que a registrou no PNJ.

Material examinado. BRASIL, Amazonas, Parque Nacional do Jaú, Rio Jaú, Carabinani, 27.iv-03.v.1995, varredura, J.A. Rafael \& J. Vidal, 9 machos; Rio Carabinani, 
Boa Vista, 020 01'05”S, 610 32'19”W, 29-31.vii.1995, J.A. Rafael \& J. Vidal, 13 machos, 5 fêmeas (todos depositados no INPA).

Registros geográficos: Guiana, Brasil (exceto região nordeste), Peru, Bolívia, Argentina.

Eubybus richardsi Smith, 1963

Espécie descrita para a Guiana e revisada recentemente por Ale-Rocha (2002a). Este é o primeiro registro da espécie no PNJ.

Material examinado. BRASIL, Amazonas, Parque Nacional do Jaú, Rio Jaú, Igarapé Miratucu, 0157’02”S, 61049'01'W, 23-28.vi.1995, varredura, J.A. Rafael \& J. Vidal, 1 macho (INPA).

Registros geográficos: Guiana, Brasil (Amapá, Amazonas).

\section{Eubybus eurypterus (Bezzi, 1909)}

Espécie descrita do Peru, revisada por Rafael \& Ale-Rocha (1995) e registrada no Parque Nacional do Jaú por Ale-Rocha (2002a).

Registros geográficos: Peru, Bolívia, Equador, Trindade, Colômbia, Brasil (Amazonas, Pará, Acre, Mato Grosso).

Eubybus symmetricus Ale-Rocha, 2002

Espécie descrita do Parque Nacional do Jaú.

Registro geográfico: Brasil (Amazonas).

Eubybus dubius Ale-Rocha, 2002

Espécie descrita do Parque Nacional do Jaú.

Registro geográfico: Brasil (Amazonas).

\section{Syneches Walker, 1852}

Diagnose. Amarelos a pretos; facetas superiores muito alargadas; fronte plana e oblíqua; pós-crânio côncavo com esclerito pós-ocelar distinto; flagelo geralmente oval, com 1 ou mais cerdas dorsais; arista pré-apical nua ou com pilosidade curta; probóscide longa, delgada com labelo esclerotinizado; pseudotraquéias ausentes; palpos cerdosos, mais curtos que a probóscide; Rs longa, surgindo próximo da h; terminália masculina simétrica.

Distribuição geográfica: cosmopolita.

\section{Syneches annulipes Bezzi, 1905}

Espécie descrita para a Bolívia e revisada por Rafael \& Ale-Rocha (1995). Este é o primeiro registro da espécie no Brasil.

Material examinado. BRASIL, Amazonas, Parque Nacional do Jaú, Rio Jaú, Novo Airão, 11-30.x.1993, J.F. Vidal, 2 machos; Carabinani, 27.iv -03.v.1995, varredura, J.A. Rafael \& J. Vidal, 1 macho; Ig[arapé] Miracutu / Ig[arapé] do
Gerlei, 0157’00”S, 61॰49’00”W, 23-28.vii.1995, Arm[adilha] Suspensa, 1 macho; Rio Papagaio, vi.2001, mata Terra Firme, 20000'3”S, 624354W, arm[adilha] Malaise, Henrique, Vidal \& Silva, 1 fêmea (todos depositados no INPA).

Registro geográfico: Bolívia, Brasil (Amazonas).

\section{Syneches hispidus sp. nov.}

(Figuras 1-7, 36)

Diagnose. Arista nua; tórax e abdome castanhoescuros; tórax com pruína castanha e uma faixa dorsal longitudinal larga de pruína cinza esparsa, estendendo-se até a notopleura; prosterno estreito; pernas com cerdas destacadas excepcionalmente longas; pernas anterior e média amarelas com coxas e tarsômero 5 castanhos; perna posterior castanha exceto base da face anterior do trocanter, 1/6 basal do fêmur e tarsômeros 1-4 amarelos, tíbia castanho-clara na base e castanha no ápice; pterostigma castanho, arredondado; abdome com longas cerdas laterais crespas.

Holótipo macho. Corpo: 4,6 mm. Asa: 3,5 mm.

Cabeça. Olhos vermelhos. Ocelos castanhos. Triângulo ocelar não protuberante. Face castanha com pruína castanha. Antena castanha; flagelo pequeno, oval com ápice arredondado, 1 cerda sub-basal dorsal, longa; pedicelo com cerdas marginais castanhas, alongadas, ultrapassando a metade do flagelo; arista castanha, nua, cerca de 2,5 vezes o comprimento da antena, mais delgada no $1 / 4$ distal. Dois pares de cerdas ocelares fracas, o anterior longo e o posterior curto. Pós-crânio preto com pruína cinza esparsa; cerdas pós-oculares esparsas, curtas e retas; pós-craniais mais longas, esparsas. Probóscide amarela a amarelo-escura; palpos castanhos com 1 cerda apical e 1 mediana ventral, longas.

Tórax. Escuto castanho-escuro com ponto mais claro na margem posterior do lobo pós-pronotal e calo pós-alar; sub-brilhante com pruína castanha e uma faixa dorsal dorsal longitudinal mediana larga de pruína cinza esparsa, estendendo-se até a notopleura; pleuras castanhas com a margem superior do catepisterno e meron amarela, laterotergito castanho-claro a amarelo, pruína castanha. Escuto alto e arredondado. Prosterno estreito. Pronoto com cerdas marginais castanhas e alongadas. Escuto com cerdas castanhas, curtas, esparsas, levemente mais longas no disco pré-escutelar; 4-6 séries acosticais e 1 série dorsocentral; 1 par dorsocentral e 1 par acrostical de cerdas longas, mais robustas e com as pontas curvadas para baixo no disco pré-escutelar; 2 notopleurais longas e robustas; 1 pós-alar curta e fraca; escutelo com cerdas longas, 1 par subapical paralelo e robusto, 1 par apical mais fraco, cerca de $2 / 3$ do comprimento do par maior, convergente, cruzando-se no ápice, e 3 cerdas laterais tão longas e fortes quanto o par apical.

Abdome. Cerca de 3,5 vezes o comprimento do tórax. Castanho-escuro, sub-brilhante, com pruína castanha 
ferrugínea esparsa. Cerdas castanhas, dorsais curtas e esparsas, laterais e ventrais muito longas e abundantes, com aspecto ondulado e as pontas curvadas. Tergito 8 curto (Figura 4); esternito 8 retangular, mais largo que longo, levemente mais estreito na base, com cerdas muito longas (Figura 5). Terminália: alongada; hipândrio longo, estreitado medialmente, com cerdas pré-apicais longas e crespas, 2 lobos distais curtos com ápices arredondados (Figura 2); epândrio com cerdas longas e crespas (Figuras 1, 3); falo delgado na metade distal, com 2 protuberâncias laterais esclerotinizadas; pós-gonitos delgados, mais curtos que o falo (Figura 2).

Pernas. Anterior e média delgadas; amarelas com coxas e tarsômeros 5 castanhos. Perna posterior robusta com fêmur fortemente dilatado, tíbia clavada e tarsômero 1 dilatado; castanha exceto base da face anterior do trocanter, $1 / 6$ basal do fêmur e tarsômeros 1-4 amarelos, tíbia castanho-clara na base escurecendo gradativamente em direção ao ápice castanho. Pernas de aspecto cerdoso, com cerdas de revestimento longas, castanho-claras a amarelas, muito longas na face posterior do fêmur médio e na tíbia posterior. Cerdas destacadas, robustas: tíbia anterior com $1 \mathrm{~A}$ pré-apical longa, alcançando o ápice do tarsômero 1; tíbia média com $1 \mathrm{AD}$ sub-basal muito longa, ultrapassando o ápice da tíbia, $1 \mathrm{P}$ e $1 \mathrm{~V}$ apicais mais delgadas, alcançando a metade do tarsômero 1; fêmur médio com cerdas delgadas e longas na face $\mathrm{PV}$; fêmur posterior com $2 \mathrm{~A}$ robustas sendo 1 mediana e 1 no $1 / 4$ distal, $7 \mathrm{AV}$ espiniformes inseridas em tubérculos grandes, face $\mathrm{V}$ com 2 espinhos pré-apicais curtos e robustos e algumas cerdas delgadas e longas, cerca de 1,5 a 2 vezes o comprimento das cerdas AV.

Asa (Figura 36): hialina, pterostigma castanho, pequeno e arredondado, próximo do ápice da r1.

Fêmea: como no macho exceto pelo fêmur posterior delgado com 7 cerdas AV espiniformes sendo 1 pré-apical e as demais distribuídas na metade distal, longas, em especial as da porção mediana de comprimento igual a 2 vezes a largura do fêmur; tarsômero 1 posterior com 4 espinhos PV amarelos; tíbia anterior sem cerdas pré-apicais anteriores. Terminália (Figuras 6,7): esternito 9 dividido longitudinalmente; cercos curtos, pequenos, ovais.

Material examinado. Holótipo macho: BRASIL, Ama[zonas]: [Novo Airão], P[ar]q[eu] N[acional] [do] Jaú / Rio Unini, Democracia / 01043'54”S, 61054’32”W / 20 24. vi.1996 / A. L. Henriques, J. / Vidal \& F. L. Oliveira / Varredura (INPA). Condição do holótipo: boa, não dissecado. Parátipos: 2 machos, 2 fêmeas, mesmos dados do holótipo; Manaus, Res. Km 41, PDBFF, 1 macho; 23-24.vi.2004, subbosque, 1 macho; 29-30.ix.2004, trilha AB B - D [dossel], 1 macho; 07-08.vii.2004, trilha LL B - SB [sub-bosque], 1 macho; 21-22.vii.2004, trilha LL I - SB [sub-bosque], 1 fêmea; 02-04.ii.2005, triolha J B - SB [sub-bosque], 1 macho; 02-04.iii.2005, trilha J I -SB [sub-bosque], 1 macho, 1 fêmea (dos depositados no INPA).

Registro geográfico: Brasil (Amazonas).

Discussão. Espécie próxima de $S$. manaos e $S$. repletus. Essas três espécies formam um grupo com abdome longo e delgado com cerdas abundantes e onduladas e tíbias anterior e média com cerdas destacadas excepcionalmente longas. Difere das mesmas pelos aspectos da terminália.

Etimologia. Do Latim, hispidus, cerdoso. Refere-se ao abdome com cerdas numerosas.

\section{Syneches jauensis sp. nov.}

(Figuras 8-14, 37)

Diagnose. Tórax e abdome castanho-escuros com pruína castanha ferrugínea esparsa; prosterno estreito; pernas longas e delgadas, anterior com coxa, trocanter e fêmur amareloescuros, tíbia e tarso castanhos, média amarelo-escura exceto tarsômeros 3-5 castanho-claros, posterior com coxa, trocanter e fêmur amarelos e tíbia e tarsos castanhos; tarsômero 1 posterior dilatado; pterostigma alongado, castanho, preenchendo o ápice da r1.

Holótipo macho. Corpo: 3,6 mm. Asa: 2,9 mm.

Cabeça. Olhos vermelhos. Ocelos amarelados. Face castanha com pruína castanha. Antena castanha exceto 1/4 basal do flagelo acinzentado; flagelo pequeno, oval, com 1 cerda mediana, dorsal, longa; pedicelo com cerdas marginais castanhas, alongadas; arista castanha com pilosidade curta nos $2 / 3$ basais, cerca de 3,5 vezes o comprimento da antena. Dois pares de cerdas ocelares fracas, o anterior longo e o posterior curto. Pós-crânio preto, sub-brilhante, com pruína ferrugínea esparsa; cerdas pós-oculares esparsas, curtas e retas; pós-craniais mais longas, esparsas. Probóscide amarela, palpo castanhoclaro com 1 cerda apical e 1 mediana ventral, longas.

Tórax. Castanho-escuro a preto com ponto amarelo no lobo pós-pronotal e calo pós-alar; pleuras castanhas a castanho-escuras. Escuto alto e arredondado. Prosterno estreito. Pronoto com cerdas marginais castanhas e curtas. Escuto com cerdas esparsas e castanhas, curtas, levemente mais longas no disco pré-escutelar; 4 séries acrosticais e 1 série dorsocentral; 1 par dorsocentral longo e forte e 1 par acrostical longo, cruzando-se apicalmente e levemente mais delgado, no disco pré-escutelar; 2 notopleurais sendo a anterior curta e a posterior longa e robusta; 1 pós-alar de comprimento médio; escutelo com cerdas longas, 1 par subapical convergente, mais longo e robusto, 1 par apical convergente, cerca de $2 / 4$ do comprimento do par subapical, e 3 cerdas laterais tão longas e fortes quanto o par apical.

Abdome. Delgado, cerca de 2,5 vezes o comprimento do tórax. Castanho-escuro com pruína castanha ferrugínea. Cerdas castanhas, dorsais curtas e esparsas, laterais mais longas. 
Tergito 8 curto (Figura 11); esternito 8 mais longo que largo com cerdas longas na margem distal (Figura 12). Terminália: robusta; hipândrio largo, estreitado distalmente com ápice truncado (Figura 9); epândrio largo com cerdas curtas de comprimento médio (Figuras 8,10); falo curto e largo com um tubérculo lateral grande com ápice esclerotinizado; pós-gonitos largos com ápice em ponta e face lateral côncava, quase tão longos quanto o falo (Figura 9).

Pernas. Alongadas e delgadas. Anterior com coxa, trocanter e fêmur amarelo-escuros, tíbia e tarso castanhos. Perna média amarelo-escura exceto tarsômeros 3-5 castanho-claros. Posterior com coxa, trocanter e fêmur amarelos, tíbia e tarsos castanhos; tíbia clavada com escova de cerdas curtas na metade distal das faces anterior, ventral e posterior; tarsômero 1 dilatado. Cerdas de revestimento castanhas. Cerdas destacadas, robustas: tíbia média com $1 \mathrm{AD}$ submediana longa, ultrapassando o ápice da tíbia, 1P apical longa ultrapassando a metade do tarsômero 1; fêmur posterior com $4 \mathrm{AV}$ pouco mais longas e discretamente mais robustas que as de revestimento, $1 \mathrm{AD}$ no $1 / 3$ distal robusta, algumas cerdas eretas alongadas e delgadas na face PV; tíbia posterior com $1 \mathrm{AD}$ mediana e $1 \mathrm{AD}$ pré-apical alongadas e fortes, 1D pré-apical e 1A apical curtas; tarsômero 1 de todas as pernas com 1 cerda $\mathrm{D}$ pré-apical robusta; tarsômero 1 posterior com 3 espinhos AV distintos.

Asa (Figura 38): asa sub-hialina com pterostigma alongado, castanho, preenchendo o ápice da r1.

Fêmea: como no macho. Terminália (Figuras 13, 14): alongada; esternito 9 longo, estreitado na base com a porção central não esclerotinizada.

Material examinado. Holótipo macho: BRASIL, Amazonas: [Novo Airão], P[ar]q[eu] N[acional] / [do] Jaú, Ig[arapé] Miratucu, Ig[arapé] / do Gerlei, 01057'00”S / 61º 49'00”W, 23-28. vii. 1995. / Arm[adilha] Malaise, J. A. I Rafael \& J. Vidal. Condição do holótipo: boa, não dissecado. Parátipos: 26 machos, 39 fêmeas (INPA), 10 machos, 10 fêmeas (MZSP), 10 machos, 10 fêmeas (MNRJ), mesmos dados do holótipo; BRASIL, Amazonas: Novo Airão, AM, 352, Igarapé Mato Grosso, 21-23.x.1994, J. Brasil, Arm. Malaise, 9 machos, 14 fêmeas (INPA).

Registro geográfico: Brasil (Amazonas).

Variação: alguns espécimes com uma cerda D mediana fraca e alongada no tarsômero 1 posterior.

Discussão. Espécie próxima de S. tomentosus Smith, 1962, do sudeste do Brasil. Difere desta pelo pterostigma mais curto e aspectos da terminália masculina.

Etimologia. O nome específico refere-se ao Parque Nacional do Jaú, localidade-tipo, onde a espécie é muito abundante.

\section{Syneches longiflagellatus sp. nov.}

(Figuras 15-21, 38)

Diagnose. Tórax amarelo com mancha dorsal quandrangular castanho-escura no $1 / 3$ anterior e pruína amarela dourada; prosterno largo; abdômen amarelo com pruína amarela dourada; pernas amarelas; pterostigma castanho-claro, pequeno e arredondado, localizado no final da veia $R 1$, veias transversais com suaves enfuscações castanhoclaras, uma faixa transversa suavemente amarronzada próximo ao ápice da asa.

Holótipo macho. Corpo: 3,6 mm. Asa: 2,9 mm.

Cabeça. Olhos vermelhos. Ocelos castanhos. Face preta com pruína acinzentada. Antena com escapo amarelo e pedicelo castanho; pedicelo com cerdas marginais castanhas, curtas; flagelo castanho, muito longo, 3,5 vezes mais longo que o escapo e pedicelo juntos, com densa pilosidade curta e 3 cerdas dorsais perto da base; arista castanha, mais curta que a antena, com pilosidade curta no $1 / 3$ basal. Dois pares de cerdas ocelares delgadas, o anterior mais longo que o posterior. Pós-crânio preto com pruína acinzentada; cerdas pós-oculares esparsas, curtas e retas; pós-craniais esparsas e pouca mais longas que as pós-oculares. Probóscide amarela, palpo amarelo com várias cerdas castanhas longas e delgadas.

Tórax. Amarelo com mancha dorsal quadrangular castanho-escura no 1/3 anterior; pruína amarela dourada. Prosterno largo. Escuto arredondado e não muito alto. Pronoto com cerdas marginais castanhas, curtas e esparsas. Cerdas amarelas, curtas, delgadas, esparsas; 4 séries acrosticais e 1 série dorsocentral; 1 par dorsocentral longo e forte no disco pré-escutelar; 2 notopleurais sendo uma anterior inferior curta e uma posterior superior longa e robusta; calo pós-alar cerdoso com 3 cerdas curtas; escutelo com 1 par subapical paralelo longo e robusto, 1 cerda apical delgada, cerca de $1 / 2$ do comprimento do par subapical, e 1 cerda lateral tão longa quanto a apical.

Abdome. Cerca de 2 vezes o comprimento do tórax. Amarelo com densa pruína amarela dourada. Cerdas castanhas a amarelas, densas e alongadas (inclusive no dorso) e mais longas nas margens lateral e distal dos tergitos. Tergito 8 curto (Figura 18); esternito 8 curto, mais largo que longo com cerdas longas (Figura 19). Terminália: robusta; hipândrio grande com dois lobos distais triangulares grandes (Figura 16); epândrio largo com cerdas de comprimento médio e protuberância lateral submediana (Figura 15, 17); falo curto e robusto, arredondado no ápice, com um tubérculo lateral mediano pontiagudo curto e esclerotizado; pós-gonitos estreitos, cerca de metade do comprimento da porção visível do falo, quase completamente encobertos pelo hipândrio (Figura 16).

Pernas. Amarelas e delgadas; cerdas de revestimento amarelas e curtas; fêmures delgados. Cerdas destacadas: tíbia 
anterior com 4-5 D longas e discretamente mais robustas que as de revestimento; tíbia média com $1 \mathrm{AD}$ no $1 / 3$ basal, escura, longa e forte, ultrapassando o ápice da tíbia, 1P mediana longa alcançando o ápice da tíbia e $1 \mathrm{P}$ apical ultrapassando a metade do tarsômero 1; fêmur posterior com 3 cerdas AV (1 no $1 / 4$ basal, 1 mediana e 1 no $1 / 4$ distal), amarelas, de comprimento igual a 2 vezes a largura do fêmur, $1 \mathrm{D}$ no $1 / 4$ distal robusta, amarelo-escura; tíbia posterior com 1D mediana longa e forte e 1D subapical do mesmo comprimento e mais delgada.

Asa (Figura 38): asa sub-hialina com iridescência dourada; pterostigma castanho-claro, pequeno e arredondado, localizado no final da veia R1; veias transversais com suaves enfuscações castanho-claras; uma faixa transversa suavemente amarronzada próximo ao ápice da asa.

Fêmea: como no macho exceto escutelo com par subapical de cerdas levemente convergente e cerda apical ausente. Terminália (Figura 20, 21): curta; cercos curtos, ovais, pequenos; esternito 9 inteiro com pequena reentrância mediana distal.

Material examinado. Holótipo macho: BRASIL, Amazonas / Parque Nacional [do] Jaú / 29.vii - 08. viii.2001 / 01054'46"S, 61035'23"W; Arm[adilha] Malaise / Campina arbustiva / Henriques \& Vidal. Condição do holótipo: boa, não dissecado. Parátipos: BRASIL, Amazonas, Parque Nacional [do] Jaú, 29.vii-08.viii.2001, 0154’46”S, 6135’23”W, Arm[adilha] Malaise, Campina arbustiva, Henriques \& Vidal, 1 macho, 1 fêmea (INPA); Igarapé Patauá, 0153’16”S, 61044'07"W, 23-28.vii.1995, varredura, J. A, Rafael \& J. F. Vidal., 1 macho (INPA); Rio Papaguaio, vi.2001, Mata Terra Firme, 20000'3"S, 62.43'54"W, Arm[adilha] Malaise, Henriques, Vidal \& Silva Leg, 1 fêmea (INPA); Novo Airão, 11-30.x.1993, J.F. Vidal, 1 fêmea (INPA); Manaus, BR 174, KM 72, Faz[enda]. Dimona, 11-14.v.1993, varredura, F.F. Xavier, 1 macho (INPA); F. P. Alegre, BR 174, KM 68, 17 19.xi.1993, F.F. Xavier, 2 machos (MNRJ); AM 010, KM 54 BI 2, 02045'33"S, 59051'03"W, 22-31-ix.1997, malaise, clareira, R.L.M. Ferreira, A.L. Henriques \& J.F. Vidal cols, 1 macho (MNRJ); PDBFF - WWF, Proj. Bert Klein, v.1985, Malaise, Reserva 1301, 1 macho (MZSP); vi.1985, Malaise, Reserva, 1301, 2 fêmeas (MZSP); vi.1985, Malaise, Reserva 1113, 1 fêmea (INPA); vii.1985, Malaise, Reserva, 1301, 1 macho, 1 fêmea (MZSP); viii.1985, Malaise, Reserva, 1301, 3 fêmeas (MZSP); ix.1985, Malaise, Reserva, 1301, 1 fêmea (INPA); x.1985, Malaise, Reserva 1112, 1 macho (INPA); x.1985, Malaise, Reserva 1301, 1 macho, 3 fêmeas (INPA); xii.1985, Malaise, Reserva 1301, 1 macho, 3 fêmeas (INPA); iii.1986, Malaise, Reserva 1301, 1 fêmea (MNRJ); v.1986, Malaise, Reserva 1301, 1 macho, 1 fêmea (INPA); iv.1986, Malaise, Reserva 1301, 1 fêmea; vii.1986, Malaise, Reserva 1301, 1 macho, 2 fêmeas (MNRJ); BR 174, ZF 6, KM 41, 04-12.xi.1991, Francisco Xavier, 1 macho, 5 fêmeas (INPA);
F. Esteio, BR 174, KM 41, ZF 3, 24-27.viii.1993, F.F. Xavier, 4 machos, 5 fêmeas (MZSP); M. S. Gabriel, Maturacá, Rio Ariabu, 31.iii-4ix.95, malaise, 1 macho (INPA); S. Gabriel [da] Cachoeira, Morro 6 lagos, 28.ix - 6.x.1990, 1 fêmea (INPA); Querari (Pelotão), 105'N, 69 51'W, 08.iv - 15.v.1993, João Vidal, 4 fêmeas (INPA).

Registro geográfico: Brasil (Amazonas).

Discussão. Espécie distinta de todas as espécies de Syneches pelo longo flagelo, caráter exclusivo da mesma.

Etimologia. Do Latim, longi + flagello, flagelo longo. Refere-se ao longo flagelo antenal, característico da espécie.

\section{Syneches manaos Smith, 1962}

Espécie descrita da cidade de Manaus, Amazonas, a qual homenageia. É uma espécie muito comum, abundantemente coletada e bem representada nas coleçôes.

Material examinado. BRASIL, Amazonas, Parque Nacional do Jaú, Novo Airão, 11-30.x.1993, J. F. Vidal, 1 macho; Rio Jaú, Meriti, 04-10.vi.1994, 2 machos; Carabinani, 27.iv-03.v.1995, varredura, J.A.Rafael, \& J.F. Vidal, 1 macho, 1 fêmea; Rio Unini, Democracia, 01042'54”S, 61054’32”W, 20-24.vi.1996, A. L. Henriques, varredura, J. Vidal, 2 machos; Rio Papagaio, vi.2001, mata Terra Firme, 2000'3”S, 62043'54”W, Henriques, Vidal e Silva, 1 macho; I[garapé] Miratuca, 15⒎'S, 61049'19'W, malaise, Aquino, 2 fêmeas (todos depositados no INPA).

Registros geográficos: Brasil (Amazonas).

\section{Syneches moraballi Smith, 1963}

Espécie descrita da Guiana. Estão entre os Hybotinae mais abundantemente coletados e encontrados em coleções. Está sendo pela primeira vez registrada no Brasil.

Material examinado. BRASIL, Amazonas, Parque Nacional do Jaú, Rio Jaú, Meriti, Novo Airão, 04-10. vi.1994, J.A.Rafael, 10 fêmeas, 13 machos; Rio Jaú, 8-iv.1994, varredura, Ruth Leila, 3 fêmeas, 2 machos; Carabinani, 27.iv-03.v.1995, varredura, J.A.Rafael \& J. Vidal, 21 fêmeas, 15 machos; Seringal, 27.iv-03.v.1995, varredura, J.A.Rafael \& J. Vidal, 3 fêmeas, 2 machos; Rio Jaú, Joca, 27.iv-03.v.1995, Arm. Malaise, J.A.Rafael \& J. Vidal, 1 fêmea; Rio Jaú, Igarapé Miratucu, 01057’02”S, 61049'01"W, 23-28.vii.1995, varredura, J.A.Rafael \& J. Vidal, 13 fêmeas, 11 machos; 29-31.vii.1995, 0201'05”S, 61032'19"W, varredura, J.A.Rafael \& J. Vidal, 1 fêmea, 4 machos; Igarapé Patauá, 01053'05”S, 61044’07”W, 23-28. vii.1995, 2 machos; Rio Carabinani, Iarapé Ipiranga, 29-31. vii.1995, 0203'05”S, 6133'32”W, Malaise, J.A.Rafael \& J. Vidal, 1 fêmea; Seringalzinho, 01050’28”, 6135'23”W, 01.viii.1995, varredura, J.A.Rafael \& J. Vidal, 6 fêmeas, 6 machos; Rio Unini, Democracia, 01043'54"S, 61054'32”W, 20-24.vi.1996, A. L. Henriques, J. Vidal \& F. L. Oliveira, 
varredura, 6 fêmeas, 5 machos; 8-16.iv.2001, 01054'46”'S, $613523 \mathrm{~W}$, Malaise, campina arbustiva, Henriques \& Vidal, 3 fêmeas, 1 macho; Rio Papagaio, vi.2001, mata Terra Firme, 2000'3"S, 62 '43'54"W, Henriques, Vidal e Silva, 10 fêmeas, 12 machos; Seringalzinho, 29.vii.08.viii.2001, 01054'46”S, 61035'23"W, Malaise, campina arbustiva, Henriques \& Vidal, 1 fêmea; Seringalzinho, 01052'34”S, 61'35'15”W, 29.vii-08. viii.2001, coleta manual, Henriques \& Vidal, 1 fêmea (todos depositados no INPA).

Registro geográfico: Guiana, Brasil (Amazonas).

\section{Syneches rafaeli sp. nov.}

(Figuras 22-28, 39)

Diagnose. Tórax castanho-claro com pruína castanha ferrugínea em vista anterior e cinza misturada com dourado no disco pré-escutelar e escutelo, em vista posterior; uma faixa dorso central anterior estreita de pruína cinza-amarelada densa, pruína castanha esbranquiçada esparsa na lateral do escuto, em vista lateral; prosterno largo; pernas amarelas exceto pela extremidade distal do fêmur posterior castanha e anel mediano largo castanho-claro na tíbia posterior; pterostigma pequeno e retangular no final da veia R1.

Holótipo macho. Corpo: 3,4 mm. Asa: 3,2 mm.

Cabeça. Olhos vermelhos. Ocelos castanho-claros. Face castanha com pruína castanha. Antena com escapo e pedicelo castanho-claros; flagelo pequeno, oval, amarelo, com 1 cerda sub-basal dorsal curta; pedicelo com cerdas marginais castanhas, curtas; arista castanha, pilosidade curta, ausente no $1 / 5$ distal, cerca de 3 vezes o comprimento da antena. Dois pares de cerdas ocelares curtas e fracas, subiguais. Pós-crânio castanho com pruína acinzentada esparsa; cerdas pós-oculares curtas, castanhas, retas; pós-craniais esparsas, mais longas que as pós-oculares. Probóscide e palpo amarelos; palpo com 1 cerda apical e 1 mediana ventral longas.

Tórax. Castanho com lobo pós-pronotal e calo pós-alar castanho-claros; pruína castanha ferrugínea em vista anterior e cinza misturada com dourado no disco pré-escutelar e escutelo em vista posterior; uma faixa dorsocentral anterior estreita de pruína cinza-amarelada densa, pruína castanha esbranquiçada esparsa na lateral do escuto, em vista lateral. Escuto alto e arredondado. Prosterno largo. Pronoto com cerdas marginais castanho-claras e curtas. Escuto com aspecto cerdoso, cerdas castanhas, de comprimento médio, mais longas no disco pré-escutelar; acrosticais multisseriadas com 1 par no disco pré-escutelar mais forte e longo, com a ponta curvada; 1 série dorsocentral com 1 par longo e forte no disco pré-escutelar, com a ponta curvada; intra-alares abundantes; 2 notopleurais longas, amplamente separadas, uma inferior e outra superior; 1 pós-alar longa e forte; escutelo com 1 par subapical longo e robusto, levemente divergente, 1 par apical mais fraco, convergente, cruzando-se no ápice, cerca de $3 / 4$ do comprimento do par subapical, e 3 cerdas laterais tão longas e fortes quanto o par apical.

Abdome. Cerca de 2 vezes o comprimento do tórax. Castanho-escuro com pruína castanha ferrugínea. Cerdas castanhas, abundantes, alongadas, mais longas nas laterais dos tergitos. Tergito 8 muito curto (Figura 25); esternito 8 grande com a margem distal reta e basal arredondada, com cerdas localizadas nos cantos distais (Figura 26). Terminália: hipândrio com dois lobos distais grandes, triangulares, com as pontas direcionadas medianamente (Figura 23); epândrio simples, alongado com cerdas de comprimento médio (Figuras 22, 24); falo alongado, robusto, profundamente fendido distalmente com dois lóbulos delgados, cada um com um grande processo digitiforme pré-apical voltado para cima; pós-gonitos largos e simples, tão longos quanto o falo (Figura 23).

Pernas. Delgadas com os fêmures discretamente dilatados. Amarelas exceto coxas e trocanteres castanho-claros, extremidade distal do fêmur posterior castanha e anel mediano largo castanho-claro na tíbia posterior. Cerdas de revestimento castanhas. Cerdas destacadas, robustas: tíbia anterior com 2-3 AD mais robustas; tíbia média com $1 \mathrm{AD}$ no $1 / 3$ basal, ultrapassando a metade do comprimento da tíbia, $1 \mathrm{P}$ apical curta, não ultrapassando a metade do tarsômero 1 ; fêmur posterior com $4 \mathrm{AV}$ e $4 \mathrm{AD}$ mais longas e robustas, $4-5 \mathrm{~V}$ na $1 / 2$ distal, curtas e espiniformes; tíbia posterior com $1 \mathrm{AD}$ mediana $1 \mathrm{AD}$ pré-apical longas e robustas.

Asa (Figura 39): amarelada, sub-hialina com pterostigma retangular castanho-claro pequeno no final da veia R1.

Fêmea: como no macho. Terminália (Figuras 27-28): alongada; cercos longos e robustos; esternito 9 estreitado na metade distal com a porção central não esclerotinizada.

Material Examinado. Holótipo macho: BRASIL, Amazonas, $\mathrm{P}[\mathrm{ar}] \mathrm{q}[\mathrm{ue}] \mathrm{N}$ [acional] / [do] Jaú, Rio Jaú, Igarapé Patauá, 01053'16”S / 61044'07”W, 23-28. vii.1995 / varredura, J. A / Rafael \& J. F. Vidal. Condição do holótipo: boa, não dissecado. Parátipos: BRASIL, Amazonas: P[ar] q[ue] N[acional] [do] Jaú, Rio Jaú, Rio Jaú, Meriti, 0410.vi.1994, J.A. Rafael, 1 fêmea (INPA); Igarapé Patauá, 01053'16"S, 61044'07'W, 23-28.vii.1995, varredura, J.A. Rafael \& J.F. Vidal, 1 macho, 1 fêmea (INPA); $\operatorname{Ig}$ [arapé] Miratucu / Ig[arapé] do Gerlei, 01057’00”S, 61049’00”W, 23-28.vii.1995, Arm[adilha] Malaise, J.A. Rafael \& J. Vidal, 2 machos, 11 fêmeas (INPA); Rio Carabinani, Boa Vista, 0201'05”S, 61032'19”W, 29-31.vii.1995, Arm[adilha] Malaise, J.A. Rafael \& J. Vidal, 1 fêmea (INPA); Rio

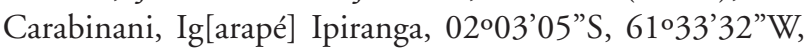
29-31.vii.1995, Arm[adilha] Malaise, J.A. Rafael \& J. Vidal, 2 fêmeas (MZSP); 29.vii.-08.viii.2001, 01054’27”S, 61035'10"W, Arm[adilha] Malaise, campina baixa, Henriques \& Vidal, 1 fêmea INPA); Rio Papaguaio, vi.2001, Mata 
Terra Firme, 2000'3”S, 62043'54”W, Arm[adilha] Malaise, Henriques, Vidal \& Silvia Leg, 1 fêmea (INPA); Manaus, PDBFF-WWF, Proj.[eto] Bert Klein, vi.1984, Malaise, Reserva 1112, 2 machos, 1 fêmea (MZSP); v.1986, Malaise, Reserva 1301, 1 fêmea (MNRJ); iv.1985, Malaise, Reserva 1301, 1 macho (MNRJ); xii.1985, Malaise, Reserva 1301, 1 fêmea (MNRJ); iii.1985, Malaise, Reserva 1301, 1 fêmea (INPA); viii.1985, Malaise, Reserva 1301, 1 macho (INPA); iv.1986, Malaise, 1 macho; vi.1985, Malaise, Reserva 1210, 1 fêmea (INPA); Manaus, F. Esteio, BR 174, KM 41, 17-20. xii.1993, F.F. Xavier, 1 macho (MNRJ); Manaus, AM 010, Km 30, 02051'47"S, 59055'51'W, F.L. Oliveira col., Arm[adilha] Malaise, 29.v-6.vi.1996, 1 fêmea (MZSP); Querari (Pelotão), $1{ }^{\circ}{ }^{\prime} \mathrm{N}$, 69051'W, 08.iv -16.v.1993, João Vidal, 2 machos, 2 fêmeas (INPA); Pará: Rio Japurá, L.[ago] Anamã, xi.1981, Robin Best, malaise, 1 macho (INPA); Marabá S. Norte, ix.1982, Michael Miles, 3 machos, 1 fêmea (INPA); Tucuruí, Rio Tocantins, Margem direita, Chiqueirão, 4-7.iv.1984, Armadilha Suspensa, chão, 1 fêmea (MPEG).

Registro geográfico: Brasil (Amazonas, Pará).

Variação: alguns espécimes apresentaram coloração levemente mais escura.

Discussão. Espécie pertencente ao grupo com fêmur posterior robusto e o prosterno largo. Difere das demais espécies do grupo pelos aspectos da terminália masculina.

Etimologia. O nome específico é dado em homenagem ao Dr. José Albertino Rafael do Instituto Nacional de Pesquisas da Amazônia - INPA, Manaus, Brasil, por sua contribuição ao conhecimento dos Empidoidea neotropicais.

Syneches repletus Bezzi, 1909.

Espécie descrita do Peru e revisada por Rafael e AleRocha (1995). Está sendo registrada pela primeira vez para o Brasil.

Material examinado. BRASIL, Amazonas, Parque Nacional do Jaú, Rio Jaú, Rio Carabinani, Boa Vista, 0201'05"S, 61'32'19"W, 23-31.vii.1995, varredura, J. A. Rafael \& J. Vidal, 2 machos (INPA).

Registros geográficos: Peru, Brasil (Amazonas).

Syneches pyramidatus Bezzi, 1905

Espécie descrita do Peru e revisada por Rafael e AleRocha (1995). Está sendo registrada pela primeira vez para o Brasil.

Material examinado. BRASIL, Amazonas, Parque Nacional do Jaú, Rio Jaú, Igarapé Miratucu, 01057’02”S, 61049’01”W, 23-28.vi.1995, varredura, J. A. Rafael \& J. Vidal, 2 machos (INPA).

Registro geográfico: Peru, Brasil (Amazonas).

\section{Syneches vidali sp. nov.}

(Figuras 29-35, 40)

Diagnose. Escuto alto, piramidal; tórax e abdômen castanhos; tórax com pruína castanha em vista anterior e pruína cinza no disco pré-escutelar, uma faixa dorsocentral estreita e manchas laterais arredondadas de pruína cinza; prosterno estreito; pernas castanhas exceto as tíbias com bases e ápices amarelos, tarsômeros 1 e 2 do tarso posterior com as extremidades amarelas, tarsômeros 3 e 4 completamente amarelos, tarsômeros 1-4 dos tarsos anterior e médio amarelos; asa suavemente acastanhada, pterostigma com duas manchas quadrangulares castanhas, uma mediana e outra no final da célula r1.

Holótipo macho. Corpo: 2,6 mm. Asa: 2,3mm.

Cabeça. Olhos vermelhos. Ocelos castanhos, triângulo ocelar protuberante. Face castanha com pruína castanha. Antena com escapo e pedicelo castanhos; flagelo pequeno, oval, castanho na metade basal e amarelo-esbranquiçado na metade distal, com 1 cerda mediana, dorsal, curta; pedicelo com cerdas marginais castanhas, curtas; arista castanha, nua, mais delgada no $1 / 5$ distal, cerca de 5 vezes o comprimento da antena. Dois pares de cerdas ocelares fracas, o anterior longo e o posterior curto. Pós-crânio castanho com pruína cinza esparsa; cerdas pós-oculares esparsas, curtas e retas; pós-craniais mais longas. Probóscide castanho-clara; palpos castanhos com 2 cerdas castanhas 1 apical e 1 mediana ventral, longas.

Tórax. Castanho exceto lobo pós-pronotal e calo pós-alar amarelos; com pruína castanha em vista anterior e pruína cinza grosseira no disco pré-escutelar e escutelo em vista posterior, uma faixa dorsocentral estreita e manchas laterais arredondadas de pruína cinza. Escuto alto, piramidal. Prosterno estreito. Pronoto com cerdas marginais castanhas e curtas. Escuto com cerdas castanhas, curtas, inconspícuas, levemente mais longas no disco pré-escutelar; 4 séries acrosticais e 1 série dorsocentral; 1 par dorsocentral longo e forte com a ponta curvada para baixo no disco pré-escutelar; 2 notopleurais longas e robustas; 1 pós-alar curta; escutelo com 1 par pré-apical longo e robusto, levemente convergente, 1 par apical fraco, convergente, cerca de $1 / 2$ do comprimento do par pré-apical, e 3 cerdas laterais tão longas e fortes quanto o par apical.

Abdome. Cerca de 2 vezes o comprimento do tórax. Castanho com densa pruína castanha. Cerdas castanhas, dorsais curtas e dorsolaterais longas. Tergito 8 curto (Figura 32); esternito 8 quadrangular, pouco mais estreito na base, com cerdas curtas (Figura 33). Terminália: hipândrio com a margem distal arredondada, duas cerdas medianas distais longas inseridas em tubérculos (Figura 30); epândrio simples, alongado, com cerdas de comprimento médio (Figuras 29, 31); falo alongado e delgado com ápice afilado; pós-gonitos largos e simples, tão longos quanto o falo (Figura 30). 

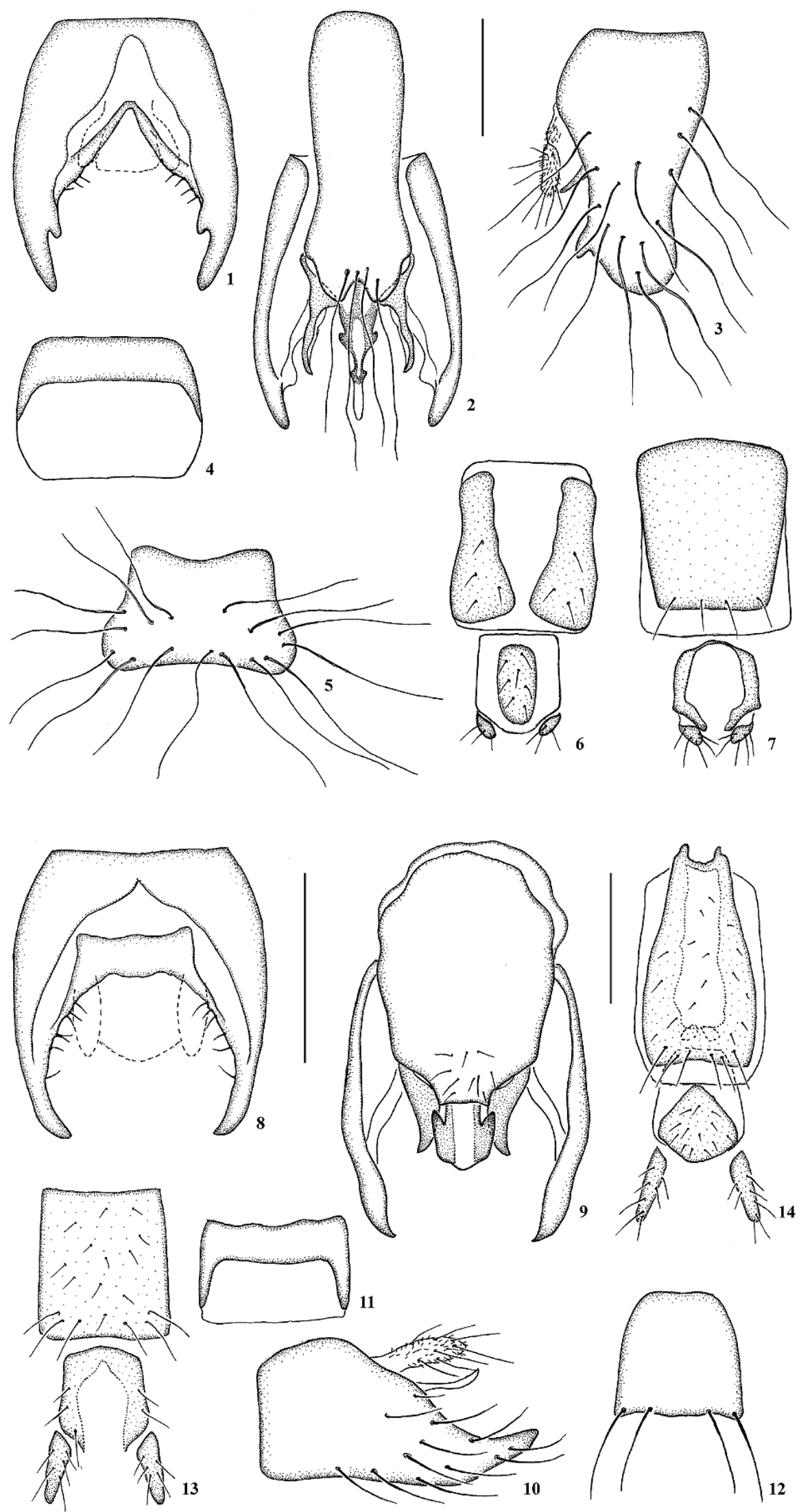

13
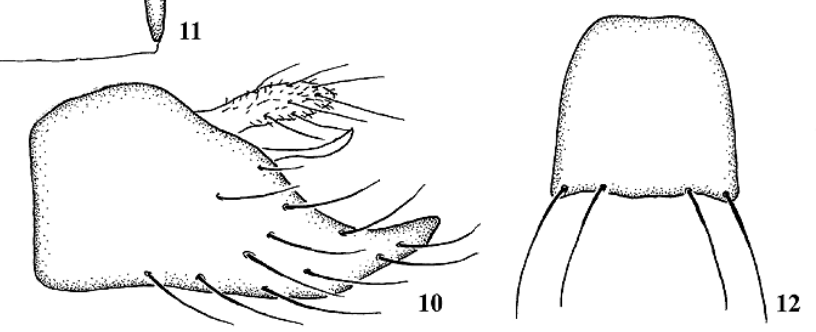

Figuras 1-7 - Syneches hispidus sp.nov. 1-3, terminália masculina: 1, epândrio, vista dorsal (cercos e hipoprocto tracejados); 2, hipândrio, pós-gonitos e falo, vista ventral; 3 , lamela epandrial direita e cerco, vista lateral. 4-5, tergito e esternito 8, respectivamente. 6-7, terminália da fêmea, vista ventral e dorsal, respectivamente. Todos na mesma escala (escala $=0,2 \mathrm{~mm}$ ).

Figuras 8-14 - Syneches jauensis sp.nov. 8-10, terminália masculina: 8, epândrio, vista dorsal (cercos e hipoprocto tracejados); 9 , hipândrio, pós-gonitos e falo, vista ventral; 10 , lamela epandrial esquerda e cerco, vista lateral. 11-12, tergito e esternito 8 , respectivamente. 13-14, terminália da fêmea, vista dorsal e ventral, respectivamente. Figuras 8-10; 11-14 na mesma escala (escala $=0,2 \mathrm{~mm}$ ). 

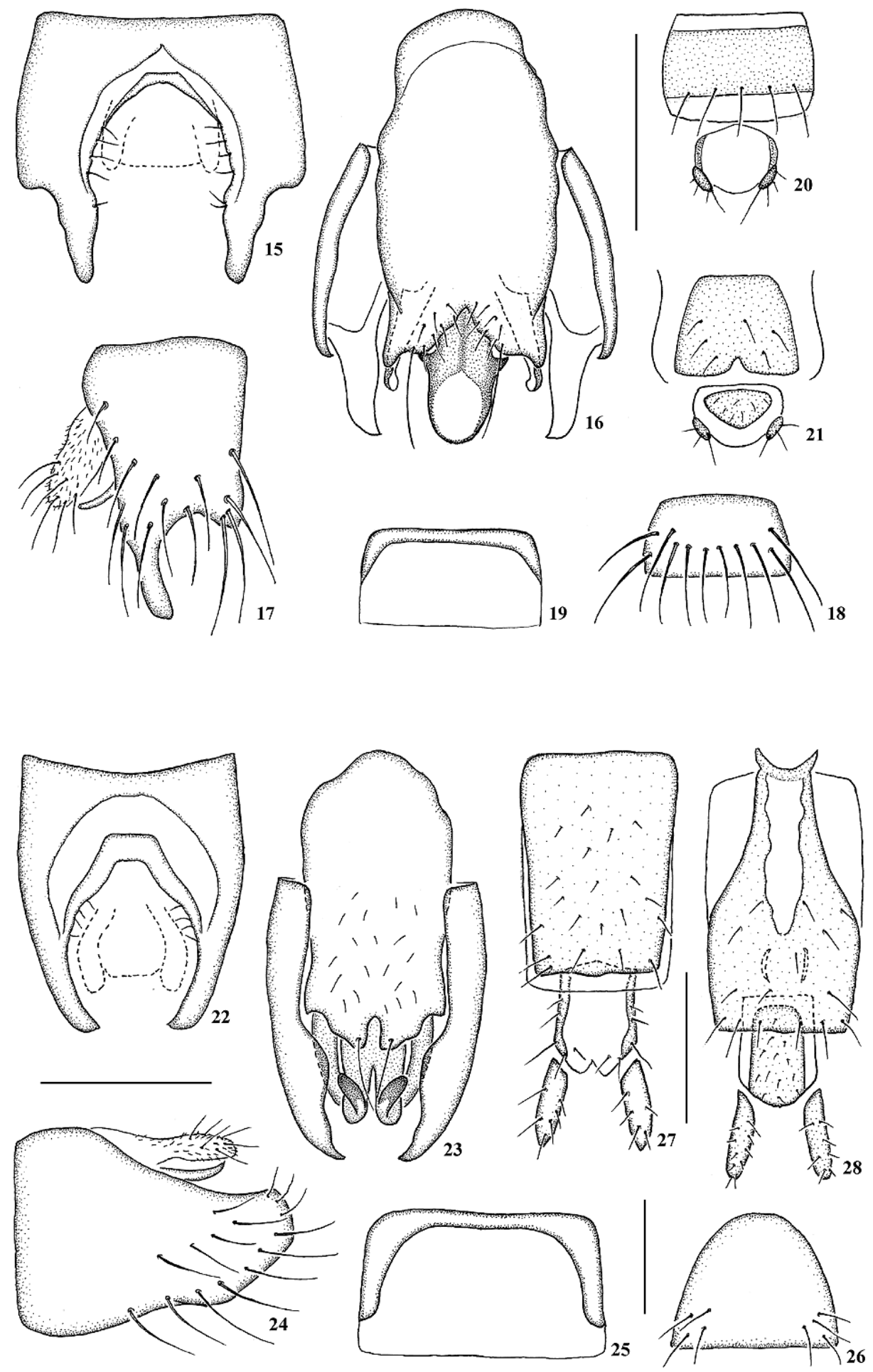

Figuras 15-21 - Syneches longiflagellatus sp.nov. 15-17, terminália masculina: 15, epândrio, vista dorsal (cercos e hipoprocto tracejados); 16 , hipândrio, pós-gonitos e falo, vista ventral; 17, lamela epandrial direita e cerco, vista lateral. 18-19, esternito e tergito 8 , respectivamente. 20-21, terminália da fêmea, vista dorsal e ventral, respectivamente. Todos na mesma escala (escala $=0,2 \mathrm{~mm}$ ).

Figuras 22-28 - Syneches rafaeli sp.n. 22-24, terminália masculina: 22, epândrio, vista dorsal (cercos e hipoprocto tracejados); 23, hipândrio, pós-gonitos e falo, vista ventral; 24 , lamela epandrial esquerda e cerco, vista lateral. 25-26, tergito e esternito 8, respectivamente. 27-28, terminália da fêmea, vista dorsal e ventral, respectivamente. Figuras 22-24; $27-$ 28 na mesma escala (escala $=0,2$ $\mathrm{mm}$ ); 25-26 na mesma escala (escala $=0,1 \mathrm{~mm}$ ). 


\section{ACTA} AMAZONICA
HYBOTINAE (DIPTERA, HYBOTIDAE) DO PARQUE NACIONAL DO JAÚ, AMAZONAS, BRASIL COM DESCRIÇÃO DE CINCO ESPÉCIES NOVAS DE Syneches Walker
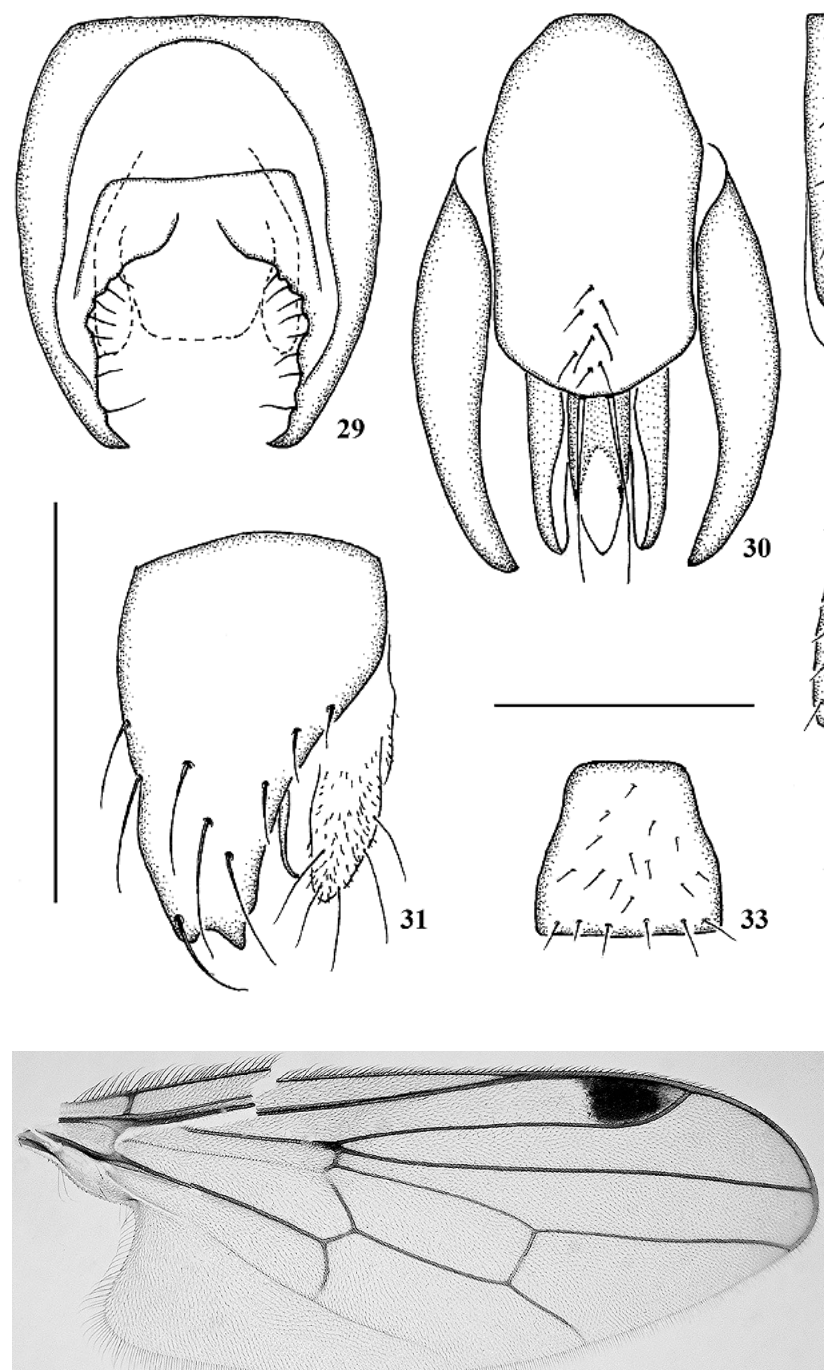

36

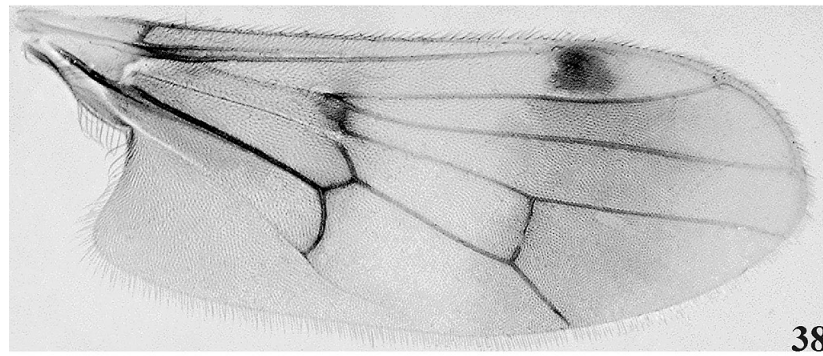

38

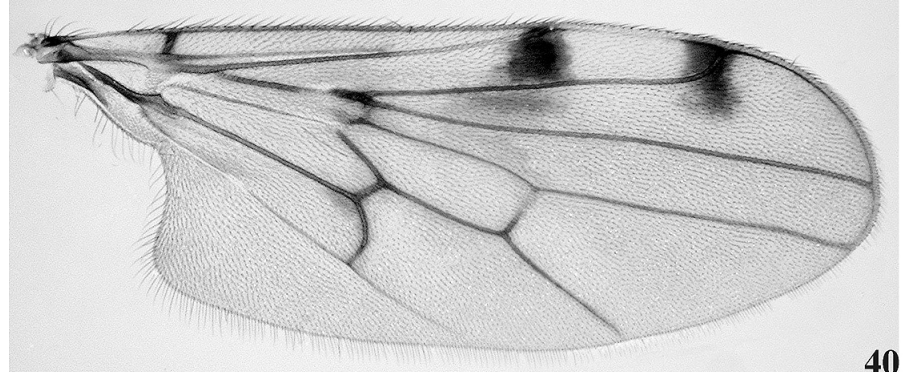

Figuras 29-35 - Syneches vidali sp.nov. 29-31, terminália masculina: 29, epândrio, vista dorsal (cercos e hipoprocto tracejados); 30, hipândrio, pósgonitos e falo, vista ventral; 31 , Iamela epandrial esquerda e cerco, vista lateral. 32-33, tergito e esternito 8 , respectivamente. 34-35, terminália da fêmea, vista dorsal e ventral, respectivamente. Figuras 29-31; 32-33;34-35 na mesma escala (escala $=0,2$ $\mathrm{mm})$.

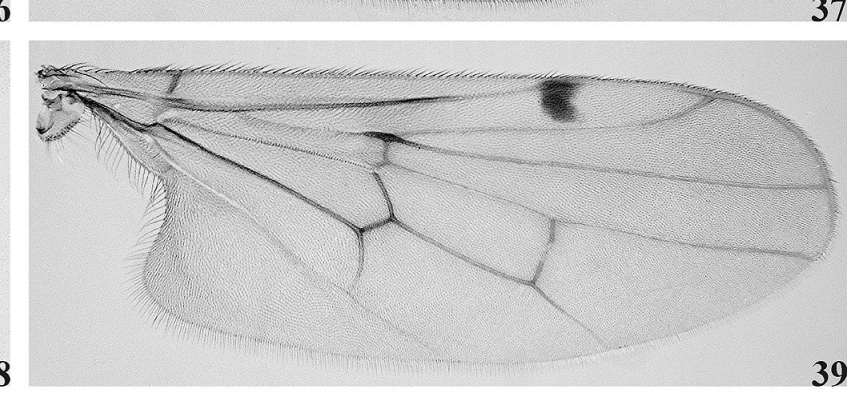

Figuras 36-40 - Asas: 36, Syneches hispidus sp.nov.; 37, Syneches jauensis sp.nov.; 38, Syneches longiflagellatus sp.nov.; 39, Syneches rafaeli sp.nov.; 40, Syneches vidali sp.nov. 
Pernas. Delgadas com fêmures fracamente dilatados. Castanhas exceto as tíbias com bases e ápices amarelos, tarsos anterior e médio com tarsômeros 1-4 amarelos, tarsômeros 1 e 2 do tarso posterior com as extremidades amarelas, tarsômeros 3 e 4 completamente amarelos. Cerdas de revestimento castanhas. Cerdas destacadas, robustas: tíbia média com $1 \mathrm{AD}$ sub-basal castanha ultrapassando a metade da tíbia, 1P apical amarela ultrapassando a metade do tarsômero 1; fêmur posterior com várias cerdas AV longas, 4-5 delas mais robustas que as demais, $1 \mathrm{~A}$ no $1 / 3$ distal, longa; tíbia média com $1 \mathrm{AD}$ mediana alcançando o ápice da tíbia e $1 \mathrm{AD}$ préapical curta.

Asa (Figura 40): suavemente acastanhada com dois pterostigmas quadrangulares castanhos, um mediano e outro no final da célula $r 1$.

Fêmea: como no macho exceto pelo fêmur delgado com 1 ou 2 cerdas AV longas, mais delgadas que no macho. Terminália (Figuras 34, 35): alongada; cercos longos e robustos; esternito 9 estreitado na metade distal com a porção central fracamente esclerotinizada.

Material examinado. Holótipo macho: BRASIL, Amazonas / Parque Nacional [do] Jaú / 29.vii - 08.viii.2001 / 01054'46"S, 6135'23"W; Arm[adilha] Malaise / campina arbustiva / Henriques \& Vidal (INPA). Condição do holótipo: boa, não dissecado. Parátipo: BRASIL, Amazonas, Parque Nacional [do] Jaú, 29.vii.-08.viii.2001, 01054’27”S, 61035'10"W, Arm[adilha] Malaise, campina baixa, Henriques \& Vidal, 2 machos (todos depositados no INPA).

Registro geográfico: Brasil (Amazonas).

Etimologia. O nome específico é dado em homenagem a João Ferreira Vidal, técnico, coletor do Instituto Nacional de Pesquisas da Amazônia - INPA, Manaus, Brasil, pela sua contribuição ao conhecimento da entomofauna amazônica.

Discussão. Espécie pertencente ao grupo de espécies com escuto em forma de pirâmide junto com as espécies $S$. pyramidatus Bezzi, S. annulipes Bezzi e S. obeliscus Bezzi. Difere destas mesmas pelos aspectos da genitália e pelo pterostigma com duas manchas distintas.

\section{CONCLUSÕES}

Syneches e Euhybus constituem os gêneros mais diversificados da subfamília Hybotinae na Região Neotropical, de acordo com o catálogo de Smith (1967) e Ale-Rocha (2002a e 2004), com 26 e 50 espécies respectivamente.

Até o momento eram conhecidas 32 espécies de Hybotinae no Brasil distribuídas nos gêneros Syneches (6), Euhybus (15), Syndyas (1), Hybos (7), Cerathybos (2) e Neohybos (1). Destas, 13 espécies já haviam sido registradas na Amazônia Brasileira: 8 de Euhybus, 1 de Syndyas, 2 de Cerathybos, 1 de Syneches e 1 de Neohybos (Smith, 1967; Ale-Rocha, 1999,
2001, 2002a,b, 2004; Ale-Rocha e Rafael, 1995; Ale-Rocha e Carvalho, 2003).

Exceto por três espécies de Euhybus, E. eurypterus Bezzi, E. dubius Ale-Rocha e E. symmetricus Ale-Rocha, já conhecidas do Parque Nacional do Jaú (Ale-Rocha, 2002a), as demais representam novos registros para esta área de conservação e as espécies $S$. annulipes, $S$. moraballi, $S$. repletus e $S$. pyramidatus são pela primeira vez registradas no Brasil.

Das espécies encontradas somente duas têm distribuição ampla, tendo sido registradas fora da região amazônica: Euhybus dimidiatus, amplamente distribuída na América do Sul e E. eurypterus, já registrada em Trindade (Ale-Rocha, 2002a).

Com este trabalho é elevado para 16 o número de espécies de Hybotinae registradas para o PNJ, sendo ampliado para $18 \mathrm{o}$ número de espécies conhecidas para a Amazônia Brasileira e 41 espécies para o Brasil. O número de espécies novas encontradas mostra o quanto o grupo ainda tem de ser trabalhado nesta região. Esses números certamente ainda não refletem a riqueza de Hybotinae do PNJ, de onde muitas espécies ainda serão conhecidas com o incremento das coletas, visto que somente algumas áreas do parque foram investigadas.

\section{AGRADECIMENTOS}

Ao Dr. Augusto Loureiro Henriques, João Ferreira Vidal e Luis Sales de Aquino, pela coleta do material no Parque Nacional do Jaú.

\section{BIBLIOGRAFIA CITADA}

Ale-Rocha, R. 1999. Descrição de Syndyas amazonica sp.n., primeiro registro do gênero na regiāo Neotropical (Diptera, Empididae, Hybotinae). Acta Amazônica, 29(2): 319-323.

Ale-Rocha, R. 2000. Smithybos, a new genus of Hybotinae (Diptera, Empididae) from Ecuador. Revista Brasileira de Entomologia, 44(1/2): 39-42.

Ale-Rocha, R. 2001. Revisão das espécies de Hybos Meigen do Novo Mundo (Diptera, Empididae). Revista Brasileira de Entomologia, 45(2): 145-165.

Ale-Rocha, R. 2002a. Revisão do gênero Eubybus Coquillett (Diptera, Empididae, Hybotinae) da Região Neotropical. Grupo dimidiatus. Acta Amazonica, 32(2): 299-324.

Ale-Rocha, R. 2002b. Descrição de duas espécies novas de Cerathybos Bezzi (Diptera, Empididae, Hybotinae). Acta Amazonica, 32(2): 293-298.

Ale-Rocha, R. 2004. Revisão das espécies sul-americanas de Euhybus (Diptera, Hybotidae, Hybotinae) do grupo purpureus. Iheringia, Serie Zoologia, 94(4): 357-373.

Ale-Rocha, R.; Rafael, J.A. 1995. Nova espécie e primeiro registro do gênero Cerathybos Bezzi no Brasil (Diptera, Empididae, Hybotinae). Revista Brasileira de Entomologia, 39(1): 189-192. 
Ale-Rocha, R;. Carvalho, C.J.B. 2003 Neohybos gen. nov. (Diptera, Empidoidea, Hybotinae) from the Neotropical Region. Zootaxa, 387:1-16.

Bezzi, M. 1905. Empididae neotropicae Musei Nationalis Hungarici. Annales historico-naturales Musei Nationalis Hungarici, 3: 424460.

Bezzi M. 1909. Beitraege zur Kenntniss der südamerikanischen Dipterenfauna. Fam. Empididae. Nova Acta Acad. Caesar Leopolino-Carolinae, 91: 297-406.

Borges, S.H; Duringan, C.C.; Pinheiro, M.R.; Camargo, J.L.C.; Murchie, A. 2004. Planejando o estudo da biodiversidade na Amazônia brasileira: uma experiência no Parque Nacional do Jaú. In: Sergio Henrique Borges; Simone Iwanaga; Carlos César Durigan; Marcos Roberto Pinheiro (Org.). Janelas para a Biodiversidade no Parque Nacional do Jaú. Uma estratégia para o estudo da biodiversidade na Amazônia. Fundação Vitória Amazônica, Manaus, Amazonas. p 3-18.

Cumming, J.M.; Sinclair, B.J.; Wood, D. M. 1995. Homology and phylogenetic implications of male genitalia in Diptera Eremoneura. Entomologica Scandinavica, 26: 121-152.

McAlpine, J.F. 1981. Morphology and terminology. In: McAlpine, J.F.; Peterson, B.V.; Shewell, G.E.; Teskey, H.J.; Vockeroth, J.R.; Wood, D.M. (Eds.). Manual of Nearctic Diptera. Volume 1, Research Branch, Agriculture Canada, Ottawa, Ontario, Canada. p. 9-63.
Rafael, J.A.; Gorayeb, I.S. 1982. Tabanidae (Diptera) da Amazônia, I - Uma nova armadilha suspensa e primeiros registros de mutucas de copas de árvores. Acta Amazonica, 12(1): 232-236.

Rafael, J.A.; Ale-Rocha, R. 1995. Revisão das espécies neotropicais de Empididae (Diptera) descritas por Mario Bezzi I. Hybotinae. Revista Brasileira de Entomologia, 39(3/4): 517-546.

Smith, K.G.V. 1962. Studies on the Brazilian Empididae (Diptera). Transactions of the Royal Entomologica Society of London (B), 114(7):195-266.

Smith, K.G.V. 1963. The Empididae (Diptera) collected on the Oxford University expeditions to British Guiana in 1929 and 1937. Proceedings of the Entomological Society of London (B), 32:153-161.

Smith, K.G.V. 1967. Family Empididae. In: A Catalogue of the Diptera of the Americas South of the United States. Volume 39, São Paulo, Departamento de Zoologia, Secretaria da Agricultura. p.1-67.

Walker, F. 1852. Diptera. In: W. W. Saunders (Ed.): Insecta Saundersiana: or characters of undescribed insects in the collection of W.W. Saunders. London, 474 p. (transcrição).

Recebido em 12/06/2007

Aceito em 25/09/2007 
